\title{
Bodyweight and body length of foetus in endothelial dys- function model pregnant mus musculus as preeclampsia induction which was given mild regular exercise
}

\author{
Meitria Syahadatina Noor ${ }^{1 *}$, Budi Santoso ${ }^{2}$, Triawanti ${ }^{3}$, Widjiati $^{4}$ \\ 1, 3 Faculty of Medicine, Lambung Mangkurat University, Banjarmasin, South Kalimantan, Indonesia \\ ${ }^{2}$ Faculty of Medicine, Airlangga University, Surabaya, East java, Indonesia \\ ${ }^{4}$ Faculty of Veterinary, Airlangga University, Surabaya, Indonesia
}

\author{
Keywords \\ Bodyweight \\ Bodylength \\ Endothelial dysfunction \\ Exercise
}

Received: 9 April 2018

Accepted: 10 May 2018

Published: 5 June 2018

\begin{abstract}
Preeclampsia is a condition with diastol blood pressure become $\geq 90 \mathrm{mmHg}$ and proteinuria in gestation more than 20 weeks. Maternal mortality in Indonesia was caused by preeclampsia as the number 2 cause. Preeclampsia is signed by endothelial dysfunction. Prevention of preeclampsia had not been developed yet. Exercise is an activity that can induce endogen anti-inflammation and antioxidants. So, it can be used to prevent the same process in preeclampsia. This research analyzed the difference of bodyweight and body length in endothelial dysfunction pregnant Mus musculus, which was given mild, regular exercise and without exercise. This research was true experimental with post-test only with control group design, consisting of 2 steps. Step 1 to know the dose of anti QA2, and step 2 to know the effect of mild, regular exercise on the body weight and bodylength of the fetus. Step 2 consisted of 4 groups (K1 for control normal pregnant, K2 for injected anti-QA2 as endothelial dysfunction model pregnant, K3 for injected anti-QA2 as endothelial dysfunction model pregnant with mild, regular exercise since early pregnancy, K4 for injected anti-QA2 as endothelial dysfunction model pregnant with mild, regular exercise since one week before pregnant). The number of Mus musculus was 6/group based on the Federer formula. Determination of anti QA2 dose to induce endothelial dysfunction was done by using some doses and examining vasoconstriction of the vessel in the uterus by HE examination. The dose that caused optimal vasoconstriction was $50 \mathrm{ng}$. The result showed there was no significant difference in body weight among all groups $(p=0.432)$, but bodyweight in K4 (0.9102 grams) was more than K2 (0.8388 grams). There was no significant difference in body length also among all of the groups $(p=0.662)$, but body length in $\mathrm{K} 4(2.1897 \mathrm{~cm})$ was longer than $\mathrm{K} 2(2.0939$ $\mathrm{cm})$. There were no significant differences in bodyweight and body length in endothelial dysfunction pregnant Mus musculus as preeclampsia induction, which was given mild, regular exercise and without exercise.
\end{abstract}

(C) 2018 The Author(s). Published by TAF Publishing.

\section{INTRODUCTION}

Preeclampsia Community Guidline (PRECOG) defined preeclampsia as condition with diastol blood pressure become more than $90 \mathrm{mmHg}$ and proteinuria in gestation more than 20 weeks $[1,2]$. Mechanism of preeclampsia related to oxidative stress, inflammation, and placentation $[3,4]$. It causes endothelial dysfunction which is marked by decrease of vasodilatation, proinflammation, and pro- thrombine dysfunction $[5,6,7,8]$. Preeclampsia model can be made by making endothelial dysfunction with injection of anti QA2 (anti Human QA Lymphocyte Antigen 2 Region). It blocked placental QA2 expression. QA2 was homolog with Human Leucocyte Antigen-G (HLA-G) in human. Low expression of HLA-G in trophoblast was the predictor od endothelial dysfunction in preeclampsia [9]. Animal model which was injected by anti QA2 had higher urine protein

*corresponding author: Meitria Syahadatina Noor

†email: drmeitria@yahoo.com 
than normal pregnant animal [10]. Effects of preeclampsia into foetus were low birth wieght, retardation of foetus growth, and intra uterine fetal death [11]. [12] stated that baby birth weight from preeclampsia mother was lower than not preeclampsia mother. Zuhrina in [12] stated that preeclampsia had risk to make low birth weight as $34 \%$. One of the indicators that can evaluate foetus growth were bodyweight and bodylength.

Effective management for preeclampsia should be prevention since early pregnant. Preeclampsia preventions that ever suggested were bedrest, regular exercise, reducing salt concumption, antioxidant, diuretic, progesterone, Nitric Oxide (NO), calcium and aspirine [13]. Regular exercise could increase cardiorespiration function that could be suitable for hypertension such as preeclampsia [13]. Mild regular exercise was exercise with low intensity and burden. [14] stated that mild regular exercise or combination of regular exercise and antiinflammation teraphy could decrease proinflammation. Proinflammation could induce endothelial dysfunction.

Mild regular exercise could induce production of interleukin 6 (IL6) that would induce interleukin 10 (IL10) [15]. It also increased endogen antioxidant [16]. Those mechanism could be the basic mechanism of prevent endothelial dysfunction in preeclampsia. the exercise could be given since before pregnant as primary prevention, and given in the early of pregnant as secondary prevention to reduce progressivity of preeclampsia mechanism. By reducing preeclampsia mechanism, its effect to foetus could be decrease also. Therefore, this research aimed to investigate the effect of mild regular exercise to bodyweight and bodylength in pregnant Mus musculus with anti QA2 injection as endothelial dysfunction model to induce preeclampsia.

\section{LITERATURE REVIEW}

Some effects of exercise related to preeclampsia were [3].

\section{A. Placental Development}

Exercise for mother was good for placental and foetus growth, to launch blood circulation, and to induce mild hypoxia to make citotrophoblast proliferation. Exercise also could increase Placental Growth Factor (PIGF) to develop placental. So, exercise balanced placental angiogenic to produce healthy foetus.

\section{B. Oxidative Stress}

Exercise stimulated antioxidant such as Glutathione peroksidase and superoxide dismutase to reduce oxidative stress. So, that process could decrease risk of preeclamp- sia.

\section{Endothelial Function}

Exercise induced the proliferation of endothelial cell, and NO sintase expression. NO sintase produced NO to give response to vasodilatation and endothelial function. Good endothelial function after exercise decreased blood pressure, so it could prevent preeclampsia.

\section{Immune and Inflammation Reaction}

Aerob exercise could reduce inflammation dan increase anti inflammation.

Preeclampsia research could be done in animal model by injecting anti QA2 to block placental QA2 expression to induce inflammation process as the basic mechanism of endothelial dysfunction to induce preeclampsia [9]. Research of [10] showed that animal model that was injected by anti QA2 had high proteinuria, urine creatinine, and urine albumin/creatinine ratio. Those conditions were similar to women in preeclampsia.

Another research that was similar to this research was about effect of mild regular exercise to foetus number in animal model. There was no significant different of foetus number in mild regular exercise and control, but descriptively if mild regular exercise was done 1 week before pregnant can increase foetus number compared with preeclampsia group without mild regular exercise [17]. The results of study about mild regular exercise and preeclampsia can be the solution of preeclampsia prevention.

\section{RESEARCH MODEL}

\section{A. Step 1}

The goal of first step was to confirm anti QA2 dose that could make endothelial dysfunction model in Mus musculus. This research used true experimental with post test only with control group design. This research used pregnant Mus musculus, 3/group. The groups of first step research were anti QA2 dose of $10 \mathrm{ng}, 20 \mathrm{ng}, 30 \mathrm{ng}, 40 \mathrm{ng}, 50$ $\mathrm{ng}$, and $60 \mathrm{ng}$. All of female Mus musculus were injected by PMSG dan HCG to syncronize oestrus cycle, anf after that the female was matted by the male $1: 1$. The next day, they were seperated and the female Mus musculus with vaginal plug were used for the research. Vaginal plug showed as day 0 of pregnant. Group 1 was injected by anti QA2 of $10 \mathrm{ng}(0,1$ $\mathrm{ml}$ ) intra peritoneal in the first day of pregnant, they were terminated in the second day of pregnant. Group 2 was injected by anti QA2 of $10 \mathrm{ng}(0,1 \mathrm{ml})$ intraperitoneal in the first and second day og pregnant, and was terminated in the third day of pregnant. Group 3 was injected by anti QA2 of $10 \mathrm{ng}(0,1 \mathrm{ml})$ intraperitoneal in the fisrt, second, and third 
day of pregnant and terminated in the fourth day. Group 4 was injected by anti QA2 of $10 \mathrm{ng}(0,1 \mathrm{ml})$ intra peritoneal in the first untill fourth day of pregnant and terminated in the fifth day of pregnant. Group 5 was injected by anti QA2 of $10 \mathrm{ng}(0,1 \mathrm{ml})$ intra peritoneal in the first untill fifth day of pregnant, and terminated in the sixth day of pregnant. Group 6 was injected by anti QA2 of $10 \mathrm{ng}(0,1 \mathrm{ml})$ intra peritoneal in the fisrt until sixth day of pregnant, and terminated in the seventh day of pregnant. Uterine of Mus musculus in each group that was terminated was taken. All of the uterines were xamined by histopathology examanation with $\mathrm{HE}$ coloration to know percentage of vasoconstriction of vessels in uterine. Optimal vasoconstriction was in $50 \mathrm{ng}$ dose of anti QA2, so it was used as dose for making endothelial dysfunction.

\section{B. Step 2}

The goal of step 2 research was to investigate bodyweight and bodylength because of mild regular exercise in endothelial dysfunction model pregnant Mus musculus. Desugn of this research was true experimental with post test only with control group design. This research used pregnant Mus musculus, the same procedure with step 1. The number of Mus musculus were 6/group. This research had 4 groups (K1 for control normal pregnant, K2 for injected anti QA2 as endothelial dysfunction model pregnant, K3 for injected anti QA2 as endothelial dysfunction model pregnant with mild regular exercise since early pregnant, K4 for injected anti QA2 as endothelial dysfunction model pregnant with mild regular exercise since 1 week before pregnant).

\section{Protocol of Mild Regular Exercise}

a. The speed was $14 \mathrm{~cm} /$ second for 15 minutes

b. The frequecy was once in teo days untill day 14 of pregnant

c. The treadmill was no angle

d. Daptation of treadmill that was used: first of all, using speed of $7 \mathrm{~cm} /$ second for 1 minute, $11 \mathrm{~cm} /$ seconds for 2 minutes, $14 \mathrm{~cm} /$ seconds for 15 minutes.

e. Before exercise, Mus musculus must be given food and drink first.

\section{Examanation of Bodyweight and Bodylength}

After termination, abdomen of Mus musculus was dissedted to get uterine, and the foetus was taken. Each foetus was cleaned first with physiological water. Foetus was weighed by digital scale twice and was calculated the mean in gram. Foetus was placed on micrometer paper. Top of head and base of the tail was signed, and after that two of those signs was measured in $\mathrm{cm}$.

\section{E. Statistic Analysis}

All of data were analyzed by normality and homogenity test. If they were in normal distribution and homogen, data were analyzed by One Way Anova with 95\% of significance level.

\section{DATA ANALYSIS}

\section{A. Step 1}

The results of step 1 research was in Figure 1, 2, and 3.

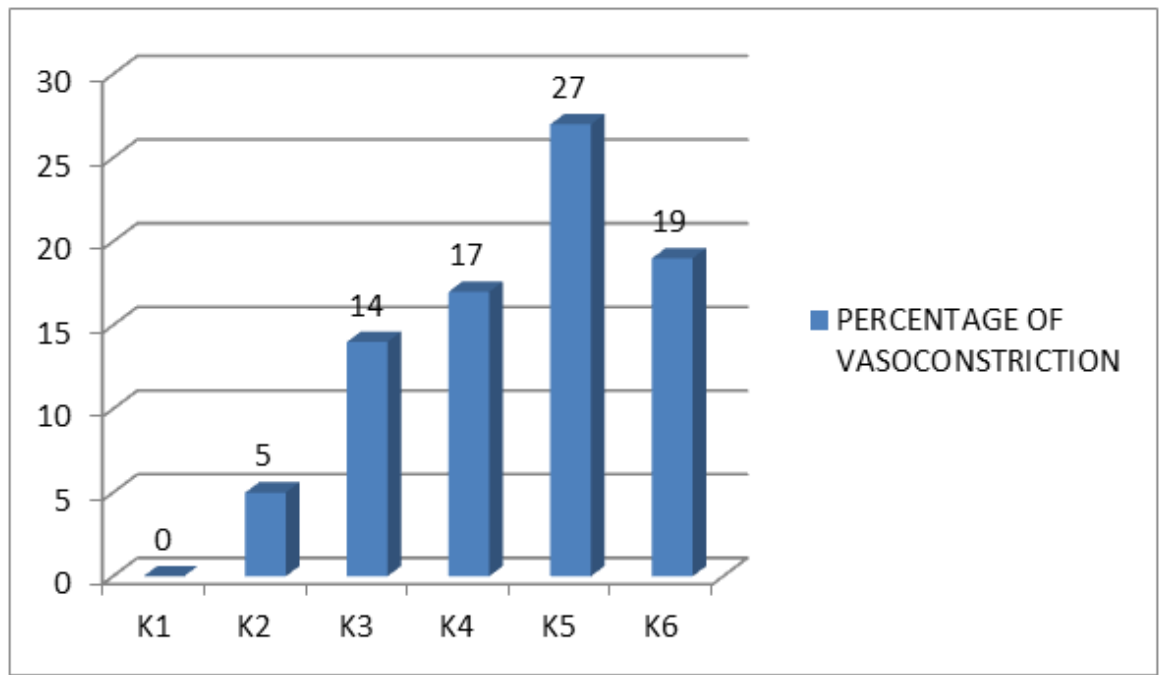

Fig. 1. Mean of uterine vessel vasoconstriction percentage 
Note: K1 (anti QA2 $10 \mathrm{ng}$ ), K2 (anti QA2 $20 \mathrm{ng}$ ), K3 (anti K6 (anti QA2 60 ng). QA2 30 ng), K4 (anti QA2 40 ng), K5 (anti QA2 50 ng), dan

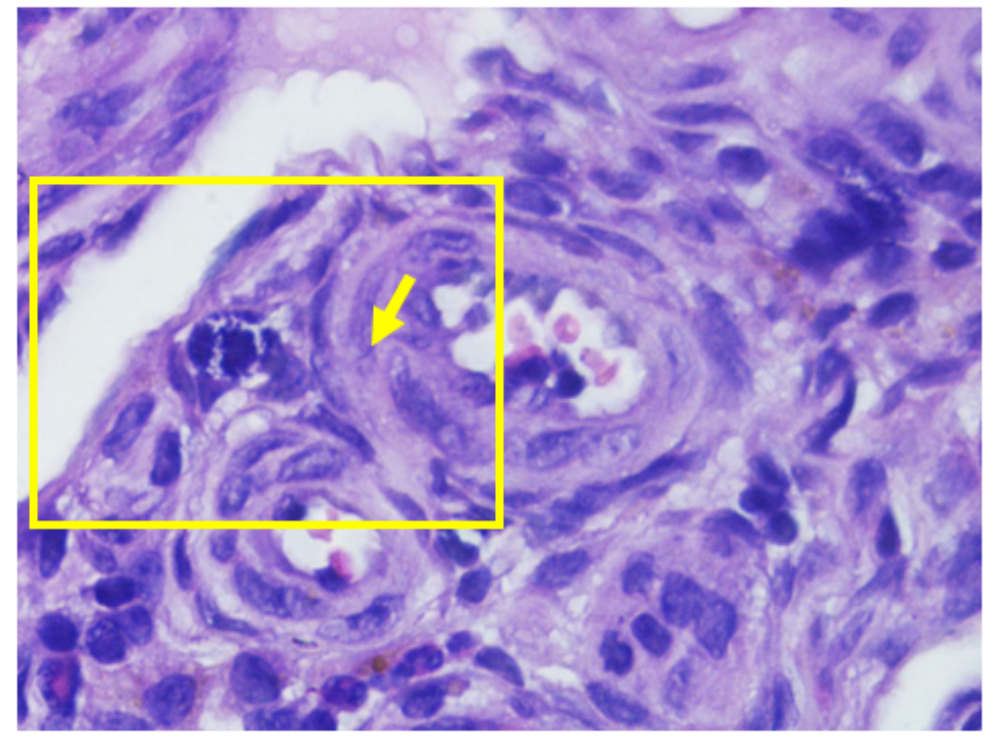

Fig. 2. Nucleus of myosit in normal arteriole wall (arrow). The shape was oval (uterine preparation; cross section; HE coloration; 1000x magnification; mikroskop Nikon H600L; camera DS Fi2 300 megapixel)

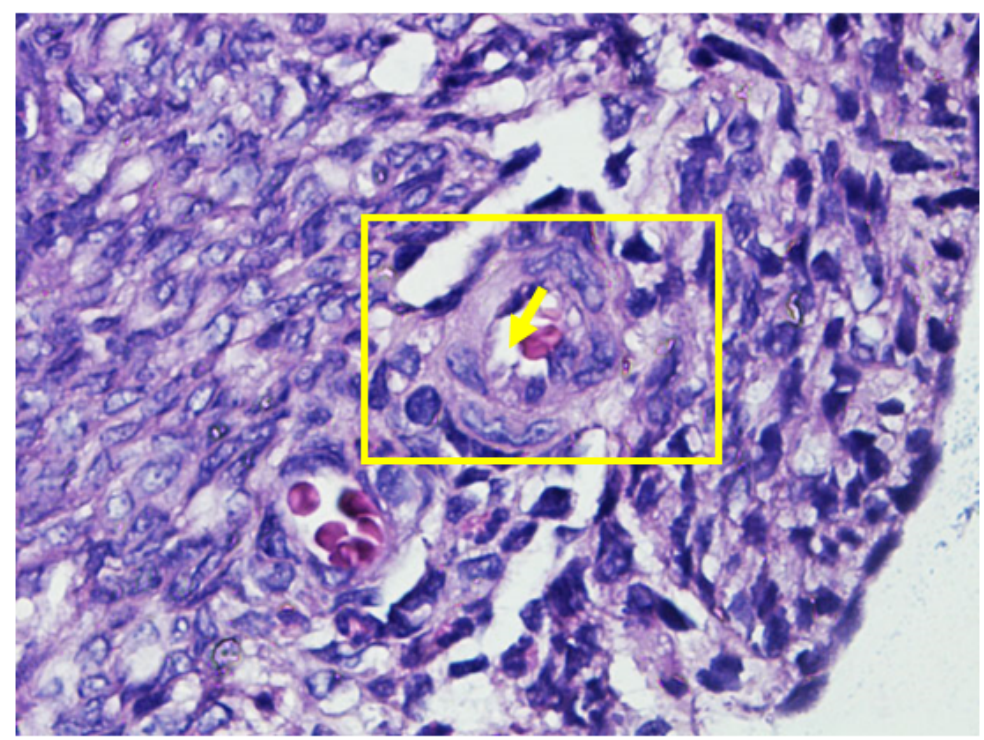

Fig. 3. Nucleus of myosit in vasoconstriction arteriole wall (arrow). The shape was notched (uterine preparation; cross section; HE coloration; 1000x magnification; mikroskop Nikon H600L; camera DS Fi2 300 megapixel)

Figure 1 showed optimal vasoconstriction percentage was in $50 \mathrm{ng}$ dose. So, this research used $50 \mathrm{ng}$ as the dose to make endothelial dysfunction to induce preeclampsia. anti QA2 injection was $10 \mathrm{ng}$ perday intraperitoneal for 5 days. Activity of vessel constraction was signed by change of myosit nucleus structure in vessel wall. In normal condition, myosit nucleus was oval (Figure 2), but in constraction condition, myosit nucleus was notched (Figure 3).

\section{B. Step 2}

Step 2 research investigated bodyweight and bodylength of the groups. The results were in Table 1 and 2 . 
TABLE 1

ANALYSIS OF FOETUS BODYWEIGHT IN ALL OF GROUPS

\begin{tabular}{llllll}
\hline \hline Group & Mean of Foetus Bodyweight (Gram) & Deviation Standard & $\boldsymbol{p}$ Value & Statistic Analysis & Alpha Value \\
\hline K1 & 0.6744 & 0.3882 & 0.432 & One way Anova & 0.05 \\
K2 & 0.8388 & 0.4207 & & & \\
K3 & 0.5979 & 0.3301 & & & \\
K4 & 0.9102 & 0.2907 & & & \\
\hline \hline
\end{tabular}

Note: (K1 for control normal pregnant, K2 for injected anti QA2 as endothelial dysfunction model pregnant, K3 for injected anti QA2 as endothelial dysfunction model pregnant with mild regular exercise since early pregnant, K4 for injected anti QA2 as endothelial dysfunction model pregnant with mild regular exercise since 1 week before pregnant)

TABLE 2

ANALYSIS OF FOETUS BODYWEIGHT IN ALL OF GROUPS

\begin{tabular}{|c|c|c|c|c|c|}
\hline Group & Mean of Foetus Bodyweight (Gram) & Deviation Standard & $p$ Value & Statistic Analysis & Alpha Value \\
\hline K1 & 1.9201 & 0.4314 & 0.662 & One way Anova & 0.05 \\
\hline $\mathrm{K} 2$ & 2.0939 & 0.4439 & & & \\
\hline K4 & 2.1897 & 0.3428 & & & \\
\hline
\end{tabular}

Note: (K1 for control normal pregnant, K2 for injected anti QA2 as endothelial dysfunction model pregnant, K3 for injected anti QA2 as endothelial dysfunction model pregnant with mild regular exercise since early pregnant, K4 for injected anti QA2 as endothelial dysfunction model pregnant with mild regular exercise since 1 week before pregnant)

All of data was in normal distribution and homogen, so analysis used One Way Anova with 95\% significancy level. Table 1 showed there was no significant differences of foetus bodyweight between all of groups. Data in Table 2 also showed that there was no significant differences of foetus bodylength in all of groups.

\section{DISCUSSION}

\section{A. Step 1}

Figure 1 showed percentage of vessel vasoconstriction. The optimal vasoconstriction was in $\mathrm{K} 5$ (dose of $50 \mathrm{ng}$ ). This dose could block placental QA2 expression that started endotelial dysfunction to induce preeclampsia.

Every Mus musculus has QA2. It was a gen to protect body immunity, so natural killer cell recognized gestation as itself. If QA2 did not be expressed, natural killer cell recognized implantation as non self and induced mother's immune reaction. It recognized implantation as Damage Associated Molecular Patterns (DAMPs). This reaction continued become endothelial dysfunction to induce preeclampsia [9].

\section{B. Step 2}

Table 1 and 2 showed that foetus bodyweight and bodylength had no significant differences. This fact showed that mild regular exercise had not effected to foetus growth yet. Some factors that were indicated such as type of exercise in pregnant condition. [18] showed that the type of mild regular exercise that could effect to other's blood pressure in pregnant was aquarobic. It increased oxygen consumption. Its frequency was twice a week for 1 hour in the third trimester. If the blood pressure was stable, circulation to foetus was also stable and it could optimize foetus growth.

If the choice of regular exercise was still treadmill, so there must be continuing study that follow duration, angle of treadmill, and the time for starting exercise. It was similar to [19]. They said that there was no significant difference in intra uterine growth restriction. In that research, the factors that were included were glucose level, frequency, duration and intensity of the exercise.

Desciptive analysis of foetus bodyweight and bodylength in Table 1 and 2 showed the different data. Mean of foetus bodyweight and bodylength in K4 (endothelial dysfunction model and given mild regular exercise since 1 week before gestation) were higher than K2 (endothelial dysfunction model by injecting anti QA2 without exercise).

From those descriptive data, the exercise 1 week before pregnant could be an early initiation for balancing process by producing antiinflammation and antioxidant. If the exercise was continued untill pregnant, it was called as chronic effectof exercise. It gave positive effect to the body. Body produced IL10 as antiinflammation and endogen antioxidant after chronic exercise. It could reduce inflammation and oxidative stress in preeclampsia. because of that process, endothelial dysfunction also reduced. So the placentation became smoother. Smooth placentation made a good 
circulation for the foetus and its growth became better.

\section{CONCLUSION}

The conclusion was there was no significant differences of bodyweight and body length in endothelial dysfunction pregnant Mus musculus as preeclampsia induction which was given mild regular exercise and whithout exercise.

This research had limitations, because the research only examined physical antrophometric, and not confirmed yet with organ abnormality. Future direction of this research was finding the preventive solution for preeclampsia to reduce its complication and maternal mortality.

\section{ACKNOWLEDGEMENT}

We would like to show our gratitude to the Embriology Laboratory, Faculty of Veterinary, Airlangga University, Surabaya, as the location of this research. We also would like to thank you for Faculty of Medicine, Lambung Mangkurat University that had given a chance to present this research in 6th International Conference on Innovation Challenges in Multidisciplinary Research and Practice (ICMRP) by Global Illuminator in Singapore 15-16th December 2018, and also greatfull for Global Illuminator to facilitate publishing this article.

\section{REFERENCES}

[1] Al-Noor M, Elazomi A, Babiker A, Babiker AM. Prevalence of hepatitis C virus antibodies among blood donors in Omdurman region in Sudan. Journal of Advances in Health and Medical Sciences. 2016;2(1):28-33. doi: https: //doi.org/10.20474/jahms-2.1.4.

[2] Milne F, Redman C, Walker J, Baker P, Bradley J, Cooper C, et al. The Pre-Eclampsia Community Guideline (PRECOG): how to screen for and detect onset of pre-eclampsia in the community. Bmj. 2005;330(7491):576-580. doi: https: //doi.org/10.1136/bmj.330.7491.576.

[3] Genest DS, Falcao S, Gutkowska J, Lavoie JL. Impact of exercise training on preeclampsia: Potential preventive mechanisms. Hypertension. 2012;60(5):1104-1109. doi: https://doi.org/10.1161/hypertensionaha.112.194050.

[4] Mendez AJP. Factors influencing stress and mental health: A comprehensive review of the literature. International Journal of Health and Medical Sciences. 2015;1(2):42-47. doi: https://doi.org/10.20469/ijhms.30004-2.

[5] Rajendran P, Rengarajan T, Thangavel J, Nishigaki Y, Sakthisekaran D, Sethi G, et al. The vascular endothelium and human diseases. International Journal of Biological Sciences. 2013;9(10):1057-1069. doi: https://doi.org/10.7150/ijbs.7502.

[6] Widmer RJ, Lerman A. Endothelial dysfunction and cardiovascular disease. Global Cardiology Science and Practice. 2014;43(3):292-308. doi: https://doi.org/10.5339/gcsp.2014.43.

[7] Sanchez-Aranguren LC, Prada CE, Riano-Medina CE, Lopez M. Endothelial dysfunction and preeclampsia: Role of oxidative stress. Frontiers in Physiology. 2014;5:372-389. doi: https://doi.org/10.3389/fphys.2014.00372.

[8] Kurniawan L. The influence of panic activation through breath holding intervention towards QEEG of social bonding. Journal of Advances in Health and Medical Sciences. 2016;2(2):70-81. doi: https://doi.org/10.20474/jahms-2.2.4.

[9] Sulistyowati S. Low Class Ib (HLA-G/Qa-2) MHC protein expression against Hsp-70 and VCAM-1 profile on preeclampsia. An observation on experimental animal mus musculus with endothelial dysfunction model. Indonesian Journal of Obstetrics and Gynecology. 2010;53(3):191-230. doi: https://doi.org/10.20473/fmi.v53i3.6446.

[10] Noor MS, Santoso B, Triawanti L, Widjiati H. Urine protein, creatinine, and uacr level in pregnant Mus musculus injected by anti QA2 as endothelial dysfunction model to induce preeclampsia. In: Presented in 2nd Syiah Kuala International Conference on Medicine and Health Sciences, Aceh, Indonesia; 2018. .

[11] Matthiesen L, Berg G, Ernerudh J, Ekerfelt C, Jonsson Y, Sharma S. Immunology of preeclampsia. Basel, Switzerland: Karger Publishers; 2005.

[12] Margareth Y, Sauqi H, Noor MS. Perbedaan berat bayi lahir dari Ibu preeklampsia berat dan tidak preeklampsia: Tinjauan terhadap RSUD ulin banjarmasin periode. Berkala Kedokteran. 2014;10(2):65-74. doi: https://doi.org/10. 33860/jik.v13i1.175.

[13] Moura S, LM L, P M, FDS C. Prevention of preeclampsia. Journal of Pregnancy. 2012;3(5):1-9. doi: https://doi.org/10. 1155/2012/435090.

[14] Hopps E, Canino B, Caimi G. Effects of exercise on inflammation markers in type 2 diabetic subjects. Acta Diabetologica. 2011;48(3):183-189. doi: https://doi.org/10.1007/s00592-011-0278-9.

[15] Gleeson M. Immune function in sport and exercise. Journal of Applied Physiology. 2007;103(2):693-699. doi: https: //doi.org/10.1152/japplphysiol.00008.2007. 
[16] Berzosa aCI C, Fuentes-Broto L, Gomez-Trullen E, Piedrafita E, Martinez-Ballarin E, Garcia JJ. Acute exercise increases plasma total antioxidant status and antioxidant enzyme activities in untrained men. BioMed Research International. 2011;3(10):1-7. doi: https://doi.org/10.1155/2011/540458.

[17] Noor MS, B S, Triawanti L, Widjiati L. Number of foetus in pregnant mus musculus which was injected by anti QA2 and given mild regular exercise: Endothelial dysfunction animal model to induce preeclampsia. In: Presented 1st Sriwijaya International Conference on Medical and Science, Palembang, Indonesia; 2018. .

[18] Kurniawati R. Pengaruh latihan aquarobik terhadp kesehatan ibu hamil di segan kecamatan gringsing kabupaten batang tahun 2014. Fakultas Ilmu Keolahragaan, Universitas Negeri Semarang, Semarang, Indonesia; 2015.

[19] Tomic V, Sporis G, Tomic J, Milanovic Z, Zigmundovac-Klaic D, Pantelic S. The effect of maternal exercise during pregnancy on abnormal fetal growth. Croatian Medical Journal. 2013;54(4):362-368. doi: https://doi.org/10.3325/cmj. 2013.54.362. 